\title{
\begin{tabular}{l|l|l} 
Jurnal Kependidikan Dasar & $\begin{array}{l}\text { Volume : } 2 \\
\text { Nomor : } 2 \\
\text { Tahun : } 2017\end{array}$ \\
\hline
\end{tabular}
}

\section{Jenis-jenis Benalu dengan Tanaman Inang Pada Ruang Terbuka Hijau Kota Surabaya}

\author{
Dina Chamidah \\ Universitas Wijaya Kusuma Surabaya \\ Surel : dina.chamidah@yahoo.co.id
}

\begin{abstract}
Green Open Space serves as a container for human life, both individually and in groups, as well as other creature containers to live and thrive in a sustainable manner. The beauty and value of the benefits of plants in the Green Open Space are often disturbed by the presence of parasites. The presence of parasites often indicates the occurrence of disturbance or damage to host plants that paraded. Benalu has been widely known by the community, but has never received attention in handling it. There has been little research on crop damage or loss caused by parasites. The purpose of this research is to know the presence or absence of parasite in green open space of Surabaya city and to know identification of dominance of parasite with the host plant in green open space of Surabaya city. Observation on the type of parasite with its host in the green open space of Surabaya City, East Java had been conducted in some spots, yield : Center Surabaya area, North Surabaya area, East Surabaya area, South Surabaya area, West Surabaya area. The observation methodology is by cruising (cruise method) by visiting the place where much overgrown vegetation plants at each point there are 500 vegetation plants which allows to be a parent host. The results of the observation obtained 3 types of parasites, 1 type of parasite of the tribe Crypteroniaceae which was parasite 39 species of host plants i.e. Henslowia frutescens .Champ. and 2 types of parasites of the tribe Loranthaceae, i.e. Loranthus Sp and Macrosolen cochinchinensis (Lour.) van Tiegh.
\end{abstract}

Key words : parasite, green open space, cruise method

\begin{abstract}
ABSTRAK
Ruang Terbuka Hijau berfungsi sebagai wadah (container) untuk kehidupan manusia, baik secara individu maupun berkelompok, serta wadah makhluk lainnya untuk hidup dan berkembang secara berkelanjutan. Keindahan dan nilai manfaat tanaman di Ruang Terbuka Hijau sering terganggu dengan adanya benalu. Keberadaan benalu sering mengindikasikan terjadinya gangguan ataupun kerusakan tumbuh-tumbuhan inang yang diparasitinya. Benalu sudah banyak diketahui oleh masyarakat, namun belum pernah mendapatkan perhatian dalam penanganannya. Selama ini belum banyak penelitian tentang kerusakan tanaman atau kerugian yang disebabkan oleh benalu.Pelaksanaan penelitian bertujuan untuk mengetahui ada atau tidaknya benalu pada ruang terbuka hijau kota Surabaya dan untuk mengetahui identifikasi dominansi benalu dengan tanaman inang yang ada di ruang terbuka hijau Kota Surabaya. Penelitian tentang jenis-jenis benalu dengan tanaman inangnya pada ruang terbuka hijau Kota Surabaya, Jawa Timur dilakukan di beberapa titik pengamatan, yaitu : Wilayah Surabaya Pusat, Wilayah Surabaya Utara, Wilayah Surabaya Timur, Wilayah Surabaya Selatan, dan Wilayah Surabaya Barat. Metodologi penelitian yang digunakan adalah metode jelajah (cruise method) dengan mendatangi tempat-tempat dimana banyak vegetasi tanaman, pada setiap satu titik terdapat 500 vegetasi tanaman yang memungkinkan menjadi inang benalu. Hasil penelitian didapatkan 3 jenis benalu, 1 jenis benalu dari suku Crypteroniaceae yaitu
\end{abstract}


84| $\mid$\begin{tabular}{l|l} 
Jural Kependidikan Dasar \\
slam Becrasis Sains
\end{tabular} Vol 2 No 2 Tahun 2017

Henslowia frutescens .Champ. yang memarasiti 39 jenis tanaman inang dan 2 jenis benalu dari suku Loranthaceae, yaitu Loranthus Sp dan Macrosolen cochinchinensis (Lour.) van Tiegh.

Kata kunci : benalu, ruang terbuka hijau, metode jelajah 


\section{A. PENDAHULUAN}

Perwujudan ruang terbuka hijau di kota Surabaya berupa taman, taman bermain anak, lapangan olahraga, dan makam, serta jalur hijau. Dari segi pemanfaatannya, ruang terbuka hijau di Kota Surabaya selain sebagai penyejuk dan elemen estetika lingkungan juga sebagian dimanfaatkan untuk sarana rekreasi dan olah raga baik pada skala lingkungan maupun kota (misalnya, taman-taman lingkungan di kawasan perumahan, taman Bungkul, lapangan TOR, lapangan Brawijaya dan Kebun Binatang Surabaya). Jalur hijau di sepanjang Kali Mas terutama di wilayah Kecamatan Genteng dimanfaatkan pula untuk arena jogging track. Kondisi ruang terbuka hijau di Kota Surabaya menunjukkan peningkatan sangat signifikan, baik dari kuantitas maupun kualitas.

Keberadaan Ruang Terbuka Hijau (RTH) di kota Surabaya sangat dibutuhkan oleh warga kota Surabaya, untuk itu diperlukan pengelolaan yang baik dengan penghijauan yang terencana serta alami sesuai fungsi dan pemeliharaan tanaman dengan baik, sehingga estetika kota akan sangat berpengaruh dalam mewujudkan lingkungan kota yang berkelanjutan.

Ruang terbuka (open spaces) merupakan ruang yang direncanakan karena kebutuhan akan tempat-tempat pertemuan dan aktivitas bersama di udara terbuka. Ruang terbuka (open spaces), Ruang Terbuka Hijau, ruang publik (public spaces) mempunyai pengertian yang hampir sama. Secara teoritis yang dimaksud dengan ruang terbuka (open spaces) adalah : ruang yang berfungsi sebagai wadah (container) untuk kehidupan manusia, baik secara individu maupun berkelompok, serta wadah makhluk lainnya untuk hidup dan berkembang secara berkelanjutan (UUPR no.24/1992).

Keindahan dan nilai manfaat tanaman pada Ruang Terbuka Hijau sering terganggu dengan adanya benalu. Benalu yang menempel pada dahan atau ranting (mengering) atau mati. Tanaman yang banyak benalunya akan tampak merana, daun hijau yang tampak bukan daun tanaman melainkan daun benalu, sehingga tanaman akan mengering dan mudah roboh sewaktu-waktu tertiup angin. Keberadaan benalu sudah banyak diketahui oleh masyarakat, namun belum pernah mendapatkan perhatian dalam pemeliharaan tanaman.

Benalu merupakan tanaman pengganggu yang bersifat parasit bagi tanaman inangnya. Keberadaan benalu dalam jumlah banyak akan mengganggu pertumbuhan dari suatu tanaman, akan tetapi seringkali benalu dilupakan oleh pengelola bidang pertanian dan kehutanan. Secara umum pemeliharaan tanaman hutan kota banyak difokuskan pada penyiraman (pengairan), pemangkasan (perantingan), dan peremajaan. Adanya pengganggu tanaman seperti hama, penyakit termasuk benalu belum mendapatkan perhatian serius. Benalu Dendrophthoe petandra diketahui memarasiti sebanyak 67 jenis tumbuhan koleksi Kebun Raya Cibodas, yang jenis-jenisnya terbagi kedalam 36 suku. Jenis-jenis yang paling banyak diparasiti adalah dari marga Ficus 
(Moraceae), sedangkan individu yang paling banyak diparasiti adalah jenis Syzygium racemosus (Myrtaceae). ${ }^{1}$

Pengukuran gangguan pada 299 cabang/ranting terlihat adanya kerusakan-kerusakan terutama pada cabang/ranting bagian distal tumbuhan yang diparasiti benalu Dendrophthoe petandra semakin besar selisih antara bagian proksimal dengan bagian distal cabang/ranting yang diparasiti benalu, maka akan semakin besar pula nilai kerusakan pada cabang/ranting tersebut. Keberadaan benalu selama ini sudah banyak diketahui dan dirasakan oleh masyarakat baik dari sisi negatif maupun nilai manfaatnya. Sebagai jenis tumbuhan parasit keberadaan benalu sering mengindikasikan terjadinya gangguan ataupun kerusakan tumbuh-tumbuhan inang yang diparasitinya, apalagi bila keberadaannya dalam jumlah yang banyak. ${ }^{2}$ Kedepan perlu banyak informasi tentang benalu untuk dapat mengelola sehingga memberikan nilai manfaat yang optimal. Selama ini belum banyak penelitian tentang benalu baik penelitian terapan maupun penelitian dasar. Berdasarkan pada masalah di atas maka dilakukan penelitian tentang jenis-jenis benalu dengan tanaman inang pada ruang terbuka hijau Kota Surabaya, Jawa Timur.

\section{B. KAJIAN PUSTAKA \\ a. Ruang Terbuka Hijau \\ Menurut Sandyohutomo, ruang} terbuka mencakup pengertian Ruang Terbuka Hijau dan ruang terbuka lainnya

\footnotetext{
${ }^{1}$ Sunaryo Sunaryo, "Identifikasi kerusakan tumbuhan di Kebun Raya Bali oleh benalu," Jurnal Teknologi Lingkungan 8, no. 2 (2011). 2 Sunaryo.
}

yang berupa kawasan tanpa bangunan di antara kawasan terbangun. ${ }^{3}$ Ruang terbuka berperan sebagai penyeimbang antara daerah terbangun dengan daerah terbuka. Berdasarkan Undang-Undang Nomor 26 Tahun 2007 tentang Penataan Ruang, yang dimaksud dengan Ruang Terbuka Hijau adalah area memanjang/jalur dan/atau mengelompok, yang penggunaannya lebih bersifat terbuka, tempat tumbuh tanaman, baik yang tumbuh secara alamiah maupun yang sengaja ditanam.

\section{b. Tumbuhan Benalu}

Benalu merupakan kelompok tumbuhan parasit yang dapat menyerang berbagai jenis tumbuhan lain. Meskipun tergolong dalam kelompok hemiparasit atau parasit fakultatif, namun ketergantungan benalu terhadap tumbuhan yang diparasitinya (tumbuhan inang) sangatlah tinggi. Kelompok ini sepanjang siklus hidupnya, dimulai dari proses perkecambahan biji hingga mencapai fase generatifnya, berinteraksi dengan tumbuhan inangnya. Benalu menjadi parasit pada berbagai jenis tumbuhan semak dan umumnya adalah jenis pohon. Jenis tumbuhan inangnya cukup beragam, mulai dari tanaman hortikultura hingga tumbuhan nonbudidaya yang terdapat di hutanhutan. ${ }^{4}$

\footnotetext{
${ }^{3}$ Mulyono Sadyohutomo, Manajemen kota dan wilayah: realita \& tantangan (Bumi Aksara, 2008).

4 Fatma Sukmawati, "Loranthaceae(Benalu)," Skripsi, diakses 10 April 2014, http://www.siafif.com/kuliah/sukma/semest er\%208/SKRIPSI_SUKMA/Loranthaceae/bah an\%20benalu/lorantus_files/vischio_data/.
} 


\section{METODE PENELITIAN \\ a. Tempat dan Waktu Penelitian}

Penelitian dilakukan di Ruang Terbuka Hijau (RTH) kota Surabaya yang di bagi menjadi 5 (lima) titik/lokasi penelitian, yakni Surabaya Timur, Surabaya Barat, Surabaya Selatan, Surabaya Utara, dan Surabaya Pusat. Penelitian dilakukan dalam waktu 3 bulan, dilaksanakan pada bulan September sampai bulan Nopember tahun 2017.

\section{b. Alat dan Bahan}

1. Alat

Adapun alat - alat yang digunakan antara lain meliputi :

1. Kamera

2. Tangga aluminium

3. Meteran

4. Gunting

5. Pisau

6. Alat-alat tulis

7. Plastik spesiment

8. Label

\section{Bahan}

Bahan-bahan yang digunakan dalam penelitian adalah :

1. Tanaman benalu

2. Tanaman inang

\section{c. Jenis Penelitian}

Penelitian ini menggunakan metode jelajah, yaitu menjelajahi lokasi yang ditetapkan menjadi area/lingkup penelitian. ${ }^{5}$ Data/pengukuran variabel

${ }^{5}$ E. A. Rugayah dan Praptiwi Widjaja, Pedoman pengumpulan data keanekaragaman flora (Bogor: LIPI, 2004). dilakukan dengan menginventarisasi /mengamati obyek sesuai dengan variabel yang diamati pada setiap unit sampel yang telah ditentukan sebagai berikut:

A. Wilayah RTH di Surabaya dipetakan menjadi lima, yaitu wilayah Surabaya Pusat, wilayah Surabaya Utara, wilayah Surabaya Timur, wilayah Surabaya Selatan, dan wilayah Surabaya Barat.

B. Masing-masing wilayah ditetapkan lima titik unit sampel dengan pola diagonal.

C. Dalam satu titik minimal terdapat 500 pohon tanaman yang memungkinkan menjadi inang benalu.

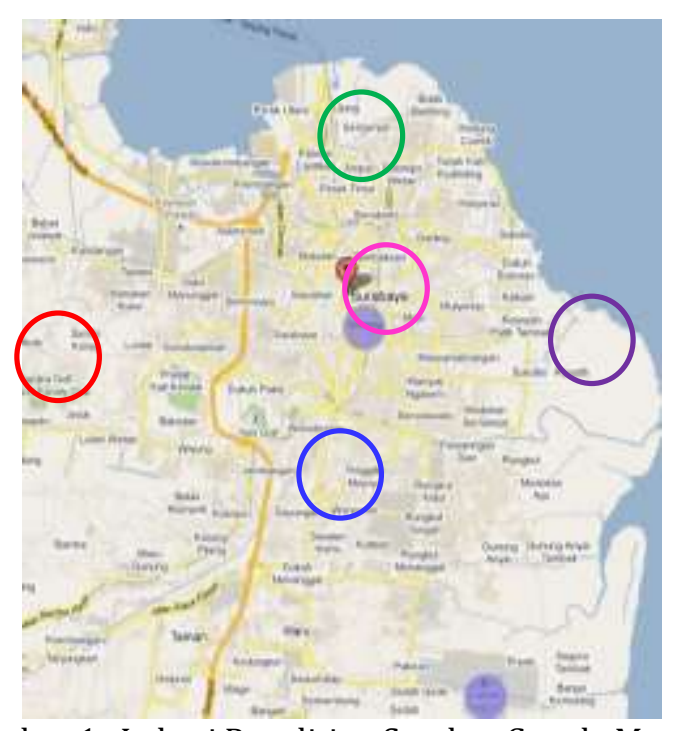

Gambar 1 . Lokasi Penelitian Sumber Google Map

Keterangan :

= Titik Surabaya Barat ( kawasan ruang terbuka hijau di perumahan Ciputra )

$O=$ Titik Surabaya Selatan ( ruang terbuka hijau masjid Al-Akbar, kompleks Gayung Sari, Wisma Pagesangan, Wisma Menanggal, Menanggal Indah ) 


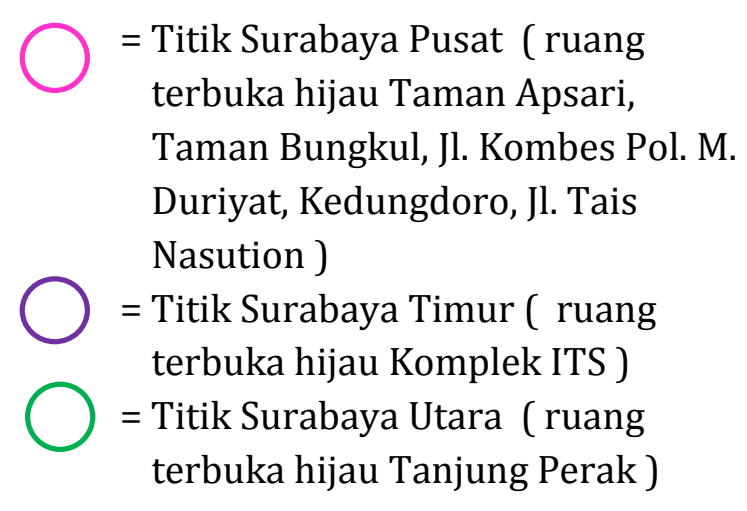

\section{Identifikasi Jenis Benalu}

Setiap benalu yang ditemukan pada setiap pengamatan unit sampel diidentifikasi bersama dengan tanaman inangnya. Pencatatan dilakukan terhadap setiap ciri morfologisnya. Untuk benalu dan tanaman inang yang belum diketahui nama jenisnya maka dibuat koleksi specimen herbarium untuk diidentifikasi di Herbarium Bogoriense. Untuk keperluan identifikasi maka penggunaan buku Backer dan Bakhuizen van den Brink $^{6}$ dan Barlow ${ }^{7}$ masih cukup relevan.

\section{E. Frekuensi kehadiran/keberadaan parasit benalu pada tanaman ruang terbuka hijau}

Pada setiap titik unit sampel (yang terdiri minimal 500 tanaman yang memungkinkan menjadi inang benalu) dilakukan pengamatan dan iventarisasi dengan mencatat nama tanaman dan

\footnotetext{
${ }^{6}$ Cornelis Andries Backer dan VAN DEN BRINK BAKHUIZEN, "Flora of Java (Spermatophytes only). Vol. 2. Angiospermae, families 111-160.," Flora of Java (Spermatophytes only). Vol. 2. Angiospermae, families 111-160., 1965.

7 Bryan A. Barlow, "A revision of the Loranthaceae of Australia and New Zealand," Australian journal of botany 14, no. 3 (1966): 421-499.
}

keberadaan benalu pada tanaman Parameter Pengamatan

Parameter pengamatan dalam penelitian ini dilakukan dengan mengamati persebaran jenis-jenis benalu pada suatu tanaman di ruang terbuka hijau Kota Surabaya, selanjutnya mengamati distribusi jenis benalu tersebut pada tanaman inang, benalu mana yang paling sering ditemukan (dominan) parasit pada suatu tanaman inang. Kemudian dilakukan identifikasi terhadap spesiman benalu tersebut.

\section{F. Analisis Data}

\section{Analisis Data Distribusi/Sebaran Benalu}

Untuk mengetahui pola sebaran benalu pada Ruang Terbuka Hijau Kota Surabaya digunakan Indeks Penyebaran Morisita (Morisita's Index Dispersion), dengan menggunakan rumus sebagai berikut $^{8}$ :

$$
I d=\frac{n\left(\sum x^{2}\right)-n}{N(N-1)}
$$

Keterangan:

Id : Indeks Penyebaran Morisita

n : Jumlah unit pengambilan contoh

$\sum x^{2} \quad$ : Jumlah individu tiap petak contoh

$\mathrm{N} \quad$ : Jumlah individu total yang diperoleh

Kriteria pola distribusi dikelompokkan sebagai berikut :

\footnotetext{
${ }^{8}$ Nurdin Muhammad Suin, Metoda Ekologi (Padang: Universitas Andalas, 2002).
} 
Id $<1 \quad$ : Penyebaran spesies seragam atau beraturan

Id = 1 : Penyebaran spesies secara acak

Id $>1$ : Penyebaran spesies berkelompok dilakukan dengan kunci identifikasi.

Pada hasil analisis pola distribusi benalu pada ruang terbuka hijau kota Surabaya, diketahui bahwa pola distribusi Loranthus Sp, Macrosolen cochinchinensis

Tabel 1. Pola distribusi benalu di ruang terbuka hijau kota Surabaya

\begin{tabular}{|c|c|c|c|c|c|c|}
\hline No & Jenis Benalu & $\mathbf{n}$ & $\mathbf{N}$ & $\sum \mathbf{X}^{2}$ & id & $\begin{array}{c}\text { Pola } \\
\text { Distribusi }\end{array}$ \\
\hline 1. & Loranthus Sp & 39 & $\begin{array}{l}258 \\
7\end{array}$ & $\begin{array}{l}271 \\
8\end{array}$ & 41,7 & Berkelompok \\
\hline 2. & $\begin{array}{l}\text { Macrosolen cochinchinensis } \\
\text { (Lour.) van Tiegh }\end{array}$ & 6 & 32 & 64 & 24,7 & Berkelompok \\
\hline 3. & Henslowia frutescens.Champ. & 1 & 90 & 299 & 11,2 & Berkelompok \\
\hline
\end{tabular}

D. HASIL DAN PEMBAHASAN

\subsection{Distribusi/ Persebaran Benalu Pada Ruang Terbuka Hijau Kota Surabaya}

Pada Keseluruhan Ruang Terbuka Hijau kota Surabaya telah diidentifikasi 3 jenis benalu, 2 jenis benalu dari suku Loranthaceae dan 1 jenis benalu dari suku Crypteroniaceae yang memarasiti 39 jenis tanaman inang yang terdapat di Ruang Terbuka Hijau kota Surabaya. Dari suku Loranthaceae ditemukan jenis benalu yakni Loranthus $S p$ dan Macrosolen cochinchinensis (Lour.) van Tiegh sedangkan dari suku Crypteroniaceae juga ditemukan satu jenis benalu yakni Henslowia frutescens .Champ. Identifikasi spesies benalu
(Lour.) van Tiegh dan Henslowia frutescens .Champ. pada setiap wilayah di ruang terbuka hijau kota Surabaya berdasarkan perhitungan indeks morisita (IsM) adalah berkelompok dengan nilai id $>1$.

Pola distribusi berkelompok pada benalu tersebut berdasarkan atas persebarannya di masing-masing wilayah Ruang Terbuka Hijau kota Surabaya. Penyebaran berkelompok terjadi karena dipegaruhi oleh beberapa faktor misalnya, spesies benalu, jenis tumbuhan inang, letak dan posisi benalu, iklim, dan faktor agen pembawa penyebaran biji benalu yang ada di masing-masing wilayah.

\subsection{Identifikasi Jenis Benalu.}

Identifikasi spesies benalu dilakukan dengan kunci identifikasi. 


\section{a. Kunci Identifikasi Jenis Benalu}

Untuk membantu dan mempermudah dalam pengenalan jenisjenis benalu di ruang terbuka hijau kota Surabaya, berikut adalah kunci identifikasi jenis benalu.

a. Kelopak Mereduksi dengan bunga dalam infloresensi bulir Loranthaceae (Loranthus Sp)

b. Kelopak berbentuk bintang dengan panjang 2-3mm $2 \mathrm{~b}$

2. a. Mahkota sebagai tunas dewasa panjang 1-1,5 cm dengan separuh bagian bawah melebar anthaceae

(Macrosolen cochinchinensis (Lour.) van Tiegh

b. Mahkota berbentuk labung dengan ujung berlepasan, panjang 2-3 cm Crypteroniaceae ( Henslowia frutescens .Champ.)

b. Deskripsi Benalu

1. Loranthus $S p$

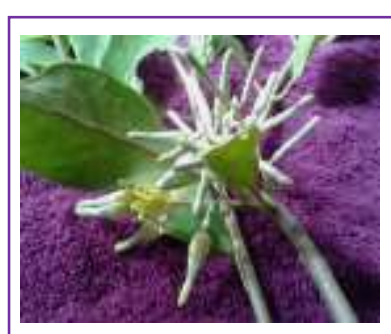

Gambar 2a. Bunga Loranthus $S p$

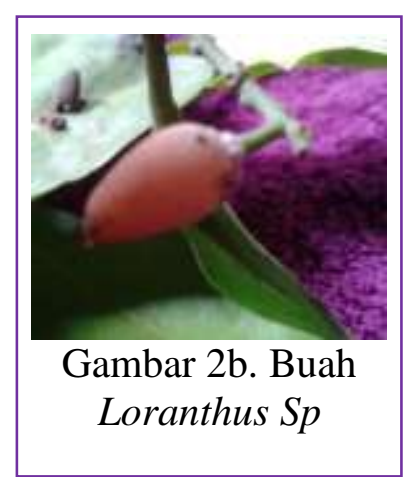

Deskripsi

Perdu, hemiparasit, agak tegar, bercabang banyak, tinggi 0,5-1,5 m. Daun agak berhadapan, bentuk bervariasi dari jorong lanset-agak bundar, panjang 6-13 $\mathrm{cm}$ dan lebar 3-8 cm, pangkal menirusmembaji, ujung tumpul - agak runcing, pertulangan menyirip dengan tulang lateral kadang-kadang melengkung, panjang tangkai daun 5-20 mm. Perbungaan tandan dengan 6-12 bunga, panjang sumbu perbungaan 10-35 mm. Bunga dengan 1 braktea di pangkal, biseksual, diklamid; kelopak mereduksi; mahkota bunga 5 merus, di bagian bawah saling berpautan, agak menggelendut, panjang 13-26 mm, menyempit membentuk leher, bagian ujung menggada, mula-mula hijau kemudian menjadi hijau kekuningan sampai kuning orange atau merah orange, panjang tabung 6-12 $\mathrm{mm}$ dan menggenta; benang sari 5, kepala sari panjang 2-5 $\mathrm{mm}$ dan tumpul serta melekat pada bagian pangkal (basifik); putik dengan kepala putik membintul. Buah bulat telur, panjang $10 \mathrm{~mm}$ dan lebar $6 \mathrm{~mm}$. Berbiji satu, biji ditutupi oleh lapisan lengket. ${ }^{9}$

2. Macrosolen cochinchinensis (Lour.) van Tiegh

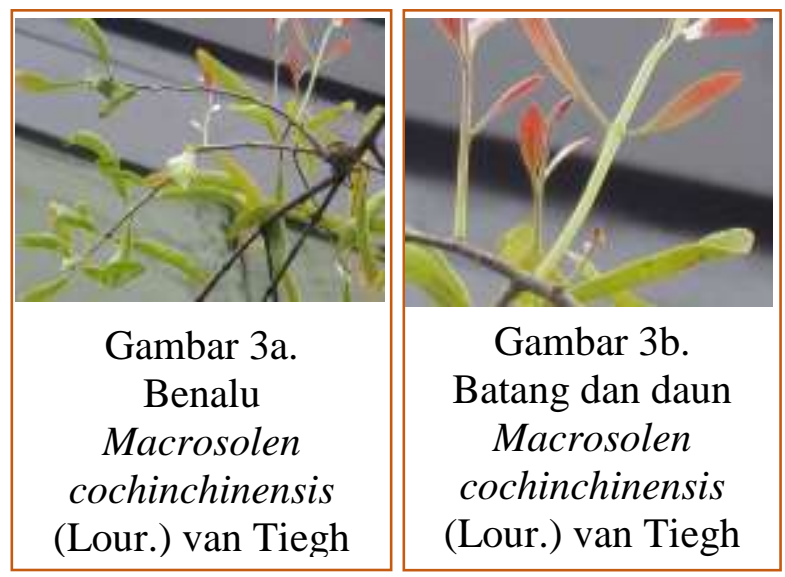

\section{Deskripsi :}

\footnotetext{
9 Tahan Uji, Sunaryo Sunaryo, dan Erlin Rachman, "Keanekaragaman jenis benalu parasit pada tanaman koleksi di Kebun Raya Eka Karya, Bali," Journal of Biological Researches 13, no. 1 (2012): 1-5.
} 
M. cochinchinensis merupakan perdu yang bercabang banyak. Ranting dengan ruas yang membesar. Daun bertangkai pendek, eliptis sampai bentuk lanset, kadang-kadang bulat telur, gundul 3,5-17 kali 1,5-7 dengan ujung yang agak meruncing, serupa kulit, mengkilat. Karangan bunga berbunga 5-7 di ketiak, kadang-kadang dalam berkas pada ruas yang tua. Tangkai bunga pendek. Tabung kelopak elipsoid, panjang lingkaran $3 \mathrm{~mm}$, pinggiran mahkota sangat pendek. Mahkota sebagai tunas dewasa 1-1,5 cm panjangnya separuh bagian bawah melebar, di tengah dengan 6 sayap, di atas menyempit menjadi buluh sempit, berakhir ke dalam gada tumpul, kuning atau hijau kekuningan, coklat tua di atas sayap, kuning sampai merah pada ujung. Taju mahkota pada akhirnya melengkung jauh kembali dan terpuntir. Bagian yang bebas dari benang sari panjangnya 3-5 mm. Kepala putik bentuk gada. Buah bulat peluru, panjang $6 \mathrm{~mm}$, akhirnya coklat violet tua. Tumbuh di atas berbagai jenis pohon. ${ }^{7}$

\section{Henslowia frutescens. Champ}
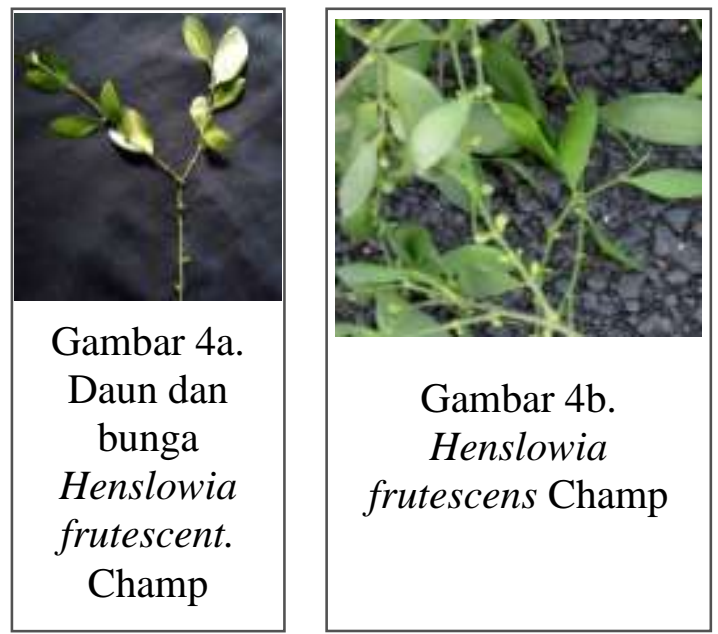

\section{Deskripsi :}

Habitat ; Terna, parasit, menahun, tinggi $30-60 \mathrm{~cm}$. Batang ; bulai, percabangan banyak, kasar, hijau kecoklatan. Daun ; tunggal, tersebar, bentuk lonjong, asimetris, ujung dan pangkal runcing, tepi rata, panjang, panjang 5-10 cm, lebar 3-8 cm, pertulangan sejajar, permukaan sedikit kasar, warna hijau. Bunga ; majemuk, bentuk tandan, terletak di ketiak daun, bunga sempurna, kelopak bentuk bintang, panjang 2-3 mm, hijau, dasar mahkota bentuk labung, ujung berlepasan, panjang 2-3 cm, putih. Buah ; Kotak. bulat, berlckuk 3, diameter 1-2 $\mathrm{cm}$, permukaan kasar, hijau. Biji ; Bentuk bulat, keras, diameter 5-8 mm, warna coklat. Akar ; Serabut, berwarna kuning kecoklatan. ${ }^{10}$

\section{SIMPULAN}

Berdasarkan penelitian yang telah dilakukan di ruang terbuka hijau kota Surabaya dapat diperoleh simpulan sebagai berikut pada ruang terbuka hijau kota Surabaya telah diidentifikasi 2 jenis benalu dari suku yang berbeda. Dari suku Loranthaceae benalu yang teridentifikasi adalah Loranthus $S p$ dan Macrosolen cochinchinensis (Lour.) van Tiegh, sedangkan dari suku Crypteroniaceae yang teridentifikasi adalah Henslowia frutescens.Champ. Jenis benalu yang mendominasi tingkat parasitasi pada suatu tanaman inang adalah benalu jenis Loranthus $S p$, dari suku Loranthaceae, yang telah memarasiti 39 jenis tanaman

\footnotetext{
10 Warintek, "Henslowia Frutescens Champ," diakses 28 Januari 2014, http://www.warintek.ristek.go.id/pangan_ke sehatan/tanaman_obat/depkes/5-038.pdf.
} 
inang dengan jumlah 2.619 benalu pada Ruang Terbuka Hijau kota Surabaya. Inang yang rentan terhadap Loranthus $S p$ didominasi oleh Pterocarpus indica.

\section{DAFTAR PUSTAKA}

Backer, Cornelis Andries, dan VAN DEN BRINK BAKHUIZEN. "Flora of Java (Spermatophytes only). Vol. 2. Angiospermae, families 111-160." Flora of Java (Spermatophytes only). Vol. 2. Angiospermae, families 111-160., 1965.

Barlow, Bryan A. "A revision of the Loranthaceae of Australia and New Zealand." Australian journal of botany 14, no. 3 (1966): 421-499.

Rugayah, E. A., dan Praptiwi Widjaja. Pedoman pengumpulan data keanekaragaman flora. Bogor: LIPI, 2004.

Sadyohutomo, Mulyono. Manajemen kota dan wilayah: realita \& tantangan. Bumi Aksara, 2008.

Suin, Nurdin Muhammad. Metoda Ekologi. Padang: Universitas Andalas, 2002. Sukmawati, Fatma.

"Loranthaceae(Benalu)." Skripsi. Diakses 10 April 2014. http://www.siafif.com/kuliah/suk ma/semester\%208/SKRIPSI_SUK MA/Loranthaceae/bahan\%20bena lu/lorantus_files/vischio_data/.

Sunaryo, Sunaryo. "Identifikasi kerusakan tumbuhan di Kebun Raya Bali oleh benalu." Jurnal Teknologi Lingkungan 8, no. 2 (2011).

Uji, Tahan, Sunaryo Sunaryo, dan Erlin Rachman. "Keanekaragaman jenis benalu parasit pada tanaman koleksi di Kebun Raya Eka Karya,
Bali." Journal of Biological

Researches 13, no. 1 (2012): 1-5.

Warintek. "Henslowia Frutescens

Champ." Diakses 28 Januari 2014. http://www.warintek.ristek.go.id/ pangan_kesehatan/tanaman_obat/ depkes/5-038.pdf. 